\title{
Human Amnion-Derived Mesenchymal Stem Cells Improved the Reproductive Function of Age-Related Diminished Ovarian Reserve in Mice Through Ampk/Foxo3a Signaling Pathway
}

\section{Hanwen Liu}

Jiangsu Province Hospital and Nanjing Medical University First Affiliated Hospital

Chunyan Jiang

Jiangsu Province Hospital and Nanjing Medical University First Affiliated Hospital

\section{Meng Cao}

Jiangsu Province Hospital and Nanjing Medical University First Affiliated Hospital

\section{Boya La}

Jiangsu Province Hospital and Nanjing Medical University First Affiliated Hospital

\section{Song Ning}

Jiangsu Province Hospital and Nanjing Medical University First Affiliated Hospital

Jing Zhou

Jiangsu Province Hospital and Nanjing Medical University First Affiliated Hospital

\section{Zhengjie Yan}

Jiangsu Province Hospital and Nanjing Medical University First Affiliated Hospital

\section{Chuyu Li}

Jiangsu Province Hospital and Nanjing Medical University First Affiliated Hospital

\section{Yugui Cui}

Jiangsu Province Hospital and Nanjing Medical University First Affiliated Hospital

\section{Xiang Ma}

Jiangsu Province Hospital and Nanjing Medical University First Affiliated Hospital

\section{Meilian Wang}

Jiangsu Province Hospital and Nanjing Medical University First Affiliated Hospital

\section{Li Chen}

Jiangsu Province Hospital and Nanjing Medical University First Affiliated Hospital

\section{Yuexin Zhang}

Jiangsu Province Hospital and Nanjing Medical University First Affiliated Hospital

Huimin Wu

Jiangsu Province Hospital and Nanjing Medical University First Affiliated Hospital Jiayin Liu

Jiangsu Province Hospital and Nanjing Medical University First Affiliated Hospital 


\section{Lianju Qin ( $\square$ ljqin@njmu.edu.cn )}

Jiangsu Province Hospital and Nanjing Medical University First Affiliated Hospital

\section{Research}

Keywords: Age-related diminished ovarian reserve, Human amnion-derived mesenchymal stem cells, Granulosa and stromal cells, AMPK/FoxO3a signaling pathway, Oxidation resistance, Mitophagy

Posted Date: February 9th, 2021

DOl: https://doi.org/10.21203/rs.3.rs-177213/v1

License: (c) (i) This work is licensed under a Creative Commons Attribution 4.0 International License. Read Full License 


\section{Abstract}

\section{Background}

Age-related diminished ovarian reserve (AR-DOR) reduced the quality of oocytes, resulting in decreased female fertility. Aging is tightly related to abnormal distribution and function of mitochondria, while mitophagy is a major process to maintain normal quality and quantity of mitochondria in cells, especially in oocytes which containing a large number of mitochondria to meet the demand of energy production during oocyte maturation and subsequent embryonic development. Ampk/FoxO3a signaling is crucial in the regulation of mitophagy. It is reported Mesenchymal stem cells (MSCs) can improve ovarian function. Here we aim to explore if human amnion-derived mesenchymal stem cells (hAMSCs) are effective in improving ovarian function in AR-DOR mice and whether Ampk/FoxO3a signaling is involved.

Methods

The AR-DOR model mice were established by 32-week-old mice with 3-8 litters, significantly low serum sex hormone levels and follicle counts. The old mice were divided into 5 treatment groups: normal saline (NS, control), $1 \%$ human serum albumin (HSA, resolver), low-dose (LD, $5.0 \times 10^{6} \mathrm{cells} / \mathrm{kg}$ ), middle-dose (MD, $\left.7.5 \times 10^{6} \mathrm{cells} / \mathrm{kg}\right)$ and high-dose (HD, $\left.10.0 \times 10^{6} \mathrm{cell} / \mathrm{sg}\right)$. The prepared hAMSCs were injected through tail vein. Serum sex hormone level, follicle counts, fertilization rate, gestation rate, little size, apoptosis of granulosa and stromal cells, expression level of Sod2, Ampk, and ratio of phosphorylated FoxO3a to total FoxO3a in ovaries were examined.

Results

Our results show that after hAMSC transplantation, the ovarian function in AR-DOR mice was significantly improved, meanwhile the apoptosis of granulosa and stromal cells in the ovaries was significantly repressed, the expression level of Ampk and the ratio of phosphorylated FoxO3a to total FoxO3a both were significantly increased, meanwhile increased Sod2 expression was also observed.

Conclusion

Our results demonstrate hAMSCs transplantation via tail-injection can improve ovarian function of ARDOR mice through Ampk/FoxO3a signaling pathway.

\section{Background}

Diminished Ovarian Reserve (DOR) in female refers to the decline in the quality and quantity of oocytes in the ovaries, accompanied by menstrual abnormalities, ovulation disorders, infertility, organs and systemic decline related of hypoestrogenic [1-3]. According to the European Association for Assisted Human Reproduction bologna Conference standards, the diagnostic criteria of DOR are anti-Mullerian hormone $(\mathrm{AMH})$ 0.5-1.1ug/L, antral follicle counting $(\mathrm{AFC})<5-7$. Currently, DOR accounts for about $10 \%$ of infertile women [1]. The causes of DOR are diverse. It is named age-related DOR (AR-DOR) when age act as the 
independent factor. According to current consensus, the age over 35 years old of a women who have fertility requirements is defined as advanced reproductive age, which can lead to AR-DOR, showing physiological ovarian degeneration [4].

Recently, AR-DOR patients are gradually increasing according to the increasing of female reproductive age [5]. However, traditional artificial assisted reproduction (ART) treatment with increased ovarian stimulation doses has been proven not to increase the live birth rate of AR-DOR women [6], and other treatments (including hormone regulation, antioxidant application, growth hormone addition etc.) neither show satisfied clinical outcomes [7-9]. Oocyte mitochondrial transplantation might be effective treatment for mitochondria disfunction is the typical symptom of AR-DOR [6], while there are still technical, ethical and regulatory limitations in the technology $[10,11]$.

It is an urgent need that exploration of new effective treatments for AR-DOR patients. Accumulation of reactive oxygen species (ROS) in the ovary is the basic pathological change and the main cause of low quality of oocytes in AR-DOR patients $[12,13]$. The excess ROS not only can increase apoptosis of granulosa and stromal cells in ovary, indirectly impeding the development and maturation of oocytes, but also harm the function of mitochondria in oocyte itself, directly restraining the maturation of oocytes [14, 15]. Thus, treatments effective in resisting ROS may promise to improve the quality of oocytes in AR-DOR patients [16]. In recent years, investigators have disclosed that transplantation of mesenchymal stem cells (MSCs) or their secretions, including placenta-derived mesenchymal stem cells (PD-MSCs) [17], human umbilical cord mesenchymal stem cells (UCMSCs) $[18,19]$, adipose derived stem cells (ADSCs) $[20,21]$ or ADSCs conditioned medium [22] all can significantly improve ovarian function in premature ovarian failure (POF) or primary ovarian insufficient (POI) models. Furthermore, it is reported that UCMSCs is function on POI patient [23]. Further explorations demonstrate that MSCs improved ovarian function through oxidation resistance in which PI3K-FoxO3a or SIRT signal pathway is involved [24, 25].

Human amnion-derived mesenchymal stem cell (hAMSC) is a type of multipotent adult stem cell isolated from the amnion which is usually treated as medical waste. Similar to other MSCs, hAMSCs possess the ability of self-renewal, differentiation, homing, and secretion of growth factors [26, 27]. So far, hAMSCs or their secretions have been showed effective in rescuing ovarian function in chemical-induced POI or POF model when directly injected into ovarian tissue via improving the follicular microenvironment and SIRT4 signaling may be involved [28-30]. However, the therapeutic potential, the dose, the mechanisms of hAMSCs on the ovary function in AR-DOR model yet not been explored.

In present study, a practical AR-DOR mouse model was first established, clinical grade hAMSCs were prepared and transplanted by tail intravenous injection, cells homing was detected, ovary function was evaluated, and oxidation resistance and mitophagy related signaling pathway were analyzed. Our results demonstrate that middle $\left(7.5 \times 10^{6}\right.$ cells $\left./ \mathrm{kg}\right)$ and high $\left(10.0 \times 10^{6} \mathrm{cell} / \mathrm{sg}\right)$ dose of hAMSCs transplantation improved the ovarian function by Ampk/FoxO3a signaling mediated mitophagy in oocytes in AR-DOR mice. 


\section{Methods}

\section{Isolation, characterization and preparation of hAMSCs}

The application of human amnions in this study was approved by the institutional ethics committee of First Affiliated Hospital, Nanjing Medical University. Human placentas were collected from healthy, normal term pregnant woman who underwent cesarean section due to simple hip circumference factors after written and informed consent was signed. Amnion-derived mesenchymal stem cells (hAMSCs) were isolated according to previous reports [31]. Briefly, amniotic membrane was sequentially removed from the placental chorionic layer under aseptic conditions, cleaned to remove the blood cells by DPBS (Gibco, A12856-01) contained Penicillin-Streptomycin (Gibco, 15140), cut into small pieces, immersed in TrypLE (Gibco, $12605-010$ ) at $37^{\circ} \mathrm{C}$ for $30 \mathrm{~min}$ with vigorously shaking. The partly digested tissues were transferred into new tubes, washed with DPBS, immersed again in fresh TrypLE at $37^{\circ} \mathrm{C}$ with vigorously shaking until digested completely. Single cells were collected by centrifuge at $1500 \mathrm{rpm}$ for $5 \mathrm{~min}$ and plated in PLT medium which composed of a-MEM medium (Gibco, 12571-063), 5\% UltraGRO-hPL (Helios Bioscience, HPCPLCRL50), 1\% L-Glutamine (Gibco, 25030) and 0.03\% Heparin Sodium (Changzhou Qianhong Bio-pharma CO.Ltd., $\mathrm{H} 32022088$ ), incubated at $37^{\circ} \mathrm{C}$ and $5 \% \mathrm{CO} 2$. Culture cells were trypsinized and passaged when $80-90 \%$ confluence observed. The cell line AMSC10 of human amnion mesenchymal stem cells (hAMSCs) was established and its identity, genetic safety, biological safety, toxicology, tumorigenicity, pluripotency, biological activity, and safe dose were completely assessed and all tested items were up to standard (submitted and under review data).

In the study, the fifth-passage hAMSCs were prepared and applied in all of transplantation experiments. Release inspection on the expression of MSCs specific surface markers, concentration of secreting cytokines in cell culture supernatant, cell viability, bacteria contamination and mycoplasma infection cells were carried out before hAMSCs transplantation. MSCs specific surface markers surface markers were detected by flow cytometry. The hAMSCs were harvested, washed, resuspended with PBS Cells were counted and diluted to $2 \times 10^{6}$ cells/100 ul. Subsequently, cells were incubated with monoclonal phycoerythrin-conjugated antibodies for human CD44 (BD, 555479), CD90 (BD, 555596), CD73 (BD, 550257), CD105 (eBioscience, 2-1057-42), CD11b (BD, 555388), CD19 (BD, 555413), CD34 (BD, 555822), CD45 (BD, 555483) and HLA-DP/DQ/DR (BD, 562008). Appropriate isotype-matched antibodies were used as negative controls. The data from 10,000 viable cells were acquired with a flow cytometer (Beckmen, NAVIOS) and analyzed using the Kaluza software (BECKMAN COULTER: version 1.3). Cell viability were calculated by cell counting using blood cell counting chamber (Reichert Bright-line, Cat.1483), bacteria contamination were assessed by endotoxin detection kit (Zhanjiang Bokang Marine Biological Co., Ltd, China) according to manufacturer's instructions, mycoplasma infection were assessed by real-time fluorescence quantitative polymerase chain reaction with specific primers (Forward primer:

GGGAGCAAACAGGATTAGATACCCT and reverse primer: TGCACCATCTGTCACTCTGTTAACCTC) on an Applied Biosystem ${ }^{\circledR}$ CO.Ltd. machine (QuantStudio ${ }^{\text {TM }} 7$ Flex Real-Time PCR System). Qualified hAMSCs 
were suspended in $1 \%$ human serum albumin (HSA), filled in $300 \mathrm{ul} /$ tube containing defined number of cells according to different does.

\section{Animals}

The application and handle of specific pathogen-free grade C57BL/6 mice was approved by the Animal Ethics Committee of Nanjing Medical University. Eight-week-old male and female and twenty-eight-weekold female C57BL/6 mice were purchased from Beijing Vital River Laboratory Animal Technology Co., Ltd. The mice were housed in the SPF-class animal room of Nanjing Medical University. The mice were grouped in 5 mice per cage, were free to eat and drink and were exposed to a day/night discontinuous illumination (12 h:12 h). The food, litter, water and cages used for feeding were strictly disinfected and sterilized.

\section{Establishment of age-related diminished ovarian reserve mouse model}

It is reported 32-week-old C57BL/6 mice are equivalent to about 35 years old of human [32], whose fertility have been proved gradually decreasing [33]. Thus the 32-week-old female mice were selected to establish the age-related DOR (AR-DOR) model. The eight-week-old female mice were set as control. Total 200 female mice at 27-week age were purchased and screened firstly by littler size after one time breeding. Then 118 old mice (32-week-old) with 3-8 litters were selected to further analysis. Venous blood sample were collected from control mice and old mice. Levels of anti-Mullerian hormone (AMH), estrogen (E2) and follicle-stimulating hormone (FSH) in serum were accessed. Furthermore, old female mice were humanely sacrificed and follicles at different development stages in ovaries were count and analyzed. The old female mice had significantly less litter size, lower levels of AMH and E2 in serum, lower numbers of secondary and antral follicles, indicating the AR-DOR model was successfully established (Fig. 2).

\section{hAMSCs transplantation and mice treatment on endpoints}

The safe dose of hAMSCs via tail vein injection in mouse is below $5.0 \times 10^{7} \mathrm{cells} / \mathrm{kg}$ body weight according to our exploration (submitted and under review data). The AR-DOR model mice were randomly assigned into 5 groups (22 mice/group): the normal saline group (NS), the $1 \%$ human serum albumin group (HSA), the low-dose group (LD, $5.0 \times 10^{6} \mathrm{cells} / \mathrm{kg}$ ), the medium-dose group (MD, $7.5 \times 10^{6} \mathrm{cell} / \mathrm{s} / \mathrm{kg}$ ), the high-douse group (HD, $1.0 \times 10^{7}$ cells/ $\mathrm{kg}$ ). Each mouse was slowly injected with $300 \mathrm{ul}$ of the corresponding preparation through the tail intravenous for total 3 times at a 4 days interval. 7 days after the last injection, 8 mice from each group were collected venous blood to perform hormone assay, and then humanely sacrificed to carried out follicles and oocyte counting, 2-cell and blastocyst formation, apoptosis analysis, histology and, immunofluorescence assay, and 6 mice from each group were humanely sacrificed to collect ovary to perform western blot assay. About 2 weeks after the last injection, the left mice from each group were humanely sacrificed to perform analysis on gestation rate and number of live fetus. 


\section{Enzyme-linked immunosorbent assay (ELISA)}

Blood was taken from the eye posterior orbital venous plexus of the mice (36-week-old) on the day 7 of the last hAMSCs transplantation. Serum was collected following centrifugation at $3000 \mathrm{rpm}$ for $15 \mathrm{~min}$ and stored at $-80^{\circ} \mathrm{C}$ before hormone analysis. The levels of E2, FSH and $\mathrm{AMH}$ were measured according to the manufacturer's guide of ELISA kit (Jining Shiye, A05182, A05021, N04308) on a Full-wavelength microplate reader (Thermo scientific, Multiskan GO).

HAMSCs culture supernatant was collected and stored at $-80^{\circ} \mathrm{C}$ for analysis. The secreting cytokines level of interleukin-6 (IL-6), fibroblast growth factor 7 (FGF7) and angiopoietin-1 (ANG-1) were measured according to the manufacturer's guide of ELISA kit (Multi Sciences, 70-EK106/2, 70-EK1262, 70-EK1122) on a Full-wavelength microplate reader (Thermo scientific, Multiskan GO).

\section{Oocyte counting, in vitrofertilization and embryo culture}

Oocytes from each group (8 mice/group) were harvested, counted and then performed in vitro fertilization and in vitro embryo culture to evaluated the effects of hAMSCs transplantation on the egg quality. A sperm suspension was prepared at least $1 \mathrm{~h}$ before fertilization. In brief, 10-weeks-old C57BL/ 6 males were sacrificed by cervical dislocation. Epididymis was dissected and cut by a single-use needle. Spermatozoa were overflowed into a drop of Human Tubal Fluid (HTF: EasyCheck, M1130) medium covered with mineral oil (Sigma, M8410) and incubated at $37^{\circ} \mathrm{C}$ for $60 \mathrm{~min}$ (for capacitation). Then the female mice which injected different preparation were humanely sacrificed by cervical dislocation. Oviducts were dissected and cut open the fallopian tube where the enlarged and bright ampulla was picked by a single-use needle and transferred in M2 media (Sigma, M7167). In vivo-matured oocytes (within cumulus follicular complex, COCs) were incubated with spermatozoa for 5 h. Zygotes were washed and cultured in KSOM (EasyCheck, M1430) embryo culture medium under mineral oil in groups of 15-20 embryos per drop (30uL). The number of zygotes after fertilization was recorded as the number of eggs obtained in mice. Embryos were cultured at $37^{\circ} \mathrm{C}$ with $5 \% \mathrm{CO} 2$. the proportion reaching the 2-cell (24-30 $\mathrm{h}$ after fertilization) and blastocyst (96-100 $\mathrm{h}$ after fertilization) stages were recorded.

\section{Ovarian morphology analysis and follicle counting}

Ovaries from each group (8 mice/group, 36-week-old) were collected at a week after the last hAMSCs transplantation, fixed in $4 \%$ paraformaldehyde at room temperature overnight, then dehydrated, embedded in paraffin, sliced into $5 \mu \mathrm{m}$ serial sections, stained with hematoxylin and eosin (H\&E) according to standard protocol. The follicles containing oocytes with a visible nucleus were counted in every fifth section of the entire ovary and were scored as primordial, primary, secondary, or antral follicles based on their morphological appearances as described previously [34]. Briefly, primordial follicles were classified as an oocyte surrounded by one layer of flattened granulosa cells, primary follicles were classified as an oocyte surrounded by one layer of cuboidal granulosa cells, secondary follicles were classified as an oocyte surrounded by more than one layer of cuboidal granulosa cells with no visible 
antrum, and antral follicle were classified as an oocyte surrounded by multiple layers of cuboidal granulosa cells and containing one or more antral spaces.

\section{Gestation rate and live fetus number assay}

The female and male mice were combined in a 2:1 cage for 2 weeks beginning from the day 7 of the last injection, and the semen plug picked up was marked as E0.5. The female mice were injected with $0.4 \%$ trypan blue solution (Gibco, 15250061) into the tail vein in E5.5, and the uterus was removed by abdominal surgery. The number of blue bands around uterine horns were counted [35] and gestation rate was calculated by formula: number of pregnant females/number of inseminated females [36].

\section{Apoptosis assay}

A TUNEL apoptosis assay kit was used to detect ovarian cell apoptosis in each group at a week after the last hAMSCs transplantation according to the manufacturer's instructions (Beyotime, C1098). Nuclei of apoptotic cells were stained dark brown. Sections were observed and imaged using an optical microscope. The apoptotic cells on sections were counted using a double-blind method and analyzed by two technicians.

\section{Histology and immunofluorescence}

Immunofluorescence experiments were carried out to trace hAMSCs homing, differentiation and evaluated the expression level of phosphorylated Fox03a in ovary after cell transplantation. Paraffinembedded sections of ovaries were dewaxed, and heat-mediated antigen retrieval was performed by microwaving for 20 min in 10 mM sodium citrate ( $\mathrm{pH}$ 6.0) (Beyotime, P0083). The sections were cooled for 15 min, washed in deionized water, rinsed in PBS, incubated in 5\% goat serum for 60 min, then incubated overnight at $4^{\circ} \mathrm{C}$ with primary antibodies of anti-human STEM121 antibody (1:100, TAKARA, Y40410), mouse anti-human CD73 antibody (1:100, Abcam, ab133582) and rabbit anti-Fox03a antibody (1:100, CST, 12829) followed by incubation with secondary antibodies of CoraLite488 conjugated Goat Anti-mouse lgG $(H+L)(1: 100$, Invitrogen, A21202) and Goat anti-rabbit lgG $(H+L)(1: 100, A b c a m$, ab150078) for $1 \mathrm{~h}$ at room temperature. DAPI (Beyotime, C1006) was used for DNA counter staining. The signals were acquired by performing the same immunostaining procedure and setting up the same parameters with a confocal microscope (Nikon, ECLIPSE Ti).

\section{Western blot}

The ovaries from NS, HSA and hAMSCs groups were pooled separately in SDS-PAGE protein loading buffer (Beyotime, P0015) and RIPA Lysis and Extraction Buffer (ThermoFisher, 89900) with protease and phosphatase inhibitor Cocktail (ThermoFisher, 78443). Then samples were denatured at $95^{\circ} \mathrm{C}$ for $10 \mathrm{~min}$ and stored at $-80^{\circ} \mathrm{C}$. After thawing, loaded on a $10 \%$ SDS-PAGE, blotted on polyvinyl fluoride (PVDF) membranes (Biorad, 1620177). Non-specific binding sites were blocked for $1 \mathrm{~h}$ at $37^{\circ} \mathrm{C}$ with $5 \%$ no-fat dry milk (BD, 2321000) in Tris-buffered saline containing 0.05\% Tween 20 (TBS-T). Membranes were incubated with polyclonal rabbit anti-Sod1 (1:1000, Abcam, ab13498), rabbit anti-Fox03a (1:1000, CST, 12829), rabbit anti-p-FoxO3a (1:1000, CST, 9466), rabbit anti-Ampk (1:1000, Abcam, ab133448) and 
rabbit anti-GAPDH (1:5000, Proteintech, 10494-1-AP) overnight at $4^{\circ} \mathrm{C}$, followed by incubation with horseradish peroxidase (HRP) conjugated anti-rabbit secondary antibody (1:1000, Abcam,ab6721) for $1 \mathrm{~h}$ at room temperature. After washing, specific immunoreactive complexes were detected by ECL kit (ThermoFisher, 32209). The bands were normalized for Gapdh using ImageJ software (NIH, Bethesda, MD, USA) and values were given as relative units. The experiment was performed in triplicate.

\section{Statistical analysis}

Each experiment was performed at least three times. All data were analyzed with SPSS20 software and are presented as mean \pm SEM. One factor t-test was used to determine significant differences among the groups. In all statistical comparisons, $\mathrm{P}<0.05$ was taken to indicate a statistically significant difference.

\section{Result}

\section{Quality control on human amnion mesenchymal stem cells}

The fifth passage of hAMSCs from identified cell line of AMSC10 were freshly prepared and release inspection on cell quality was carried before transplantation. The expression levels of mesenchymal stem cells (MSCs) specific surface molecular markers were evaluated and cytokines in cell culture supernatant were detected to identify and assess biological activity of hAMSCs respectively. Our result showed a high expression of CD44 (98.33 $\pm 0.66 \%), C D 73(97.27 \pm 0.97 \%)$, D90 (98.58 $\pm 0.18 \%), C D 105(97.68 \pm 0.17 \%)$ and a no or very low expression of CD11b (1.21 $\pm 0.06 \%)$ CD19 $(0.00 \pm 0.00 \%), C D 34(0.00 \pm 0.00 \%), C D 45$ $(0.00 \pm 0.00 \%), \mathrm{HLA}-\mathrm{DP} / \mathrm{DQ} / \mathrm{DR}(0.66 \pm 0.53 \%)$ (Fig. 1a). Also, high concentrations of secreting cytokines of IL-6 $(9655 \pm 917 \mathrm{pg} / \mathrm{ml})$, FGF7 $(775.1 \pm 30.01 \mathrm{pg} / \mathrm{ml})$ and ANG-1 $(10505 \pm 344.3 \mathrm{pg} / \mathrm{ml})$ were detected in cell culture supernatant (Fig. 1b). Meanwhile, prepared hAMSCs showed a high viability $(96.6 \pm 0.6 \%)$ and negative bacteria contamination and mycoplasma infection (Fig. 1c). Above data indicated a high quality of prepared hAMSCs.

\section{Establishment of age-related diminished ovarian reserve mouse model}

According to previous report, 32-week-old C57BL/ 6 mice are equivalent to about 35 years old of human [32], whose fertility have been proved gradually decreasing [33]. Here the 32-week-old mice were selected establish the age-related diminished ovarian reserve (AR-DOR) model. And 12-week-old female mice were set as young control (YC). The averaged littler size of the AR-DOR mice was significantly less than that of YC mice ( $8.2 \pm 1.0$ vs $5.4 \pm 1.4, p<0.05)$ (Fig. 2a). The AR-DOR mice also showed significantly decreased levels of AMH $(394.6 \pm 90.2 \mathrm{pg} / \mathrm{ml}$ vs $325.3 \pm 50.9 \mathrm{pg} / \mathrm{ml}, p<0.05)$ and $\mathrm{E} 2(4.2 \pm 1.2 \mathrm{pmol} / \mathrm{L}$ vs $3.3 \pm 0.6$ $\mathrm{pmol} / \mathrm{L}, p<0.05)$, while had an increased level of $\mathrm{FSH}(1.9 \pm 0.4 \mathrm{mlU} / \mathrm{ml}$ vs $3.2 \pm 0.6 \mathrm{mlU} / \mathrm{ml}, p>0.05)$ in serum compare to the YC mice (Fig. 2a). Follicle counting results showed that the selected AR-DOR mice with decreased number of primordial ( $8.3 \pm 2.1$ vs $12.9 \pm 7.4, p>0.05)$, primary $(8.1 \pm 3.2$ vs $11.8 \pm 6.5, p>$ $0.05)$, secondary $(12.9 \pm 5.2$ vs $25.5 \pm 6.9, p<0.05)$ and antral $(3.1 \pm 2.5$ vs $7.9 \pm 2.9, p<0.05)$ follicles 
compare to YC mice (Fig. 2b). Thus, age-related diminished ovarian reserve (AR-DOR) mouse model was established, which with significantly less litter size, lower levels of AMH and E2 in serum, and smaller number of follicles in ovary (Fig. 2).

\section{hAMSCs transplantation andin vivotracing}

In the study, relative low doses of hAMSCs were application cause AR-DOR mice are physical healthy. The AR-DOR mice were divided into 5 treatment groups and injected preparations: normal saline (NS, control), $1 \%$ human serum albumin (HSA, resolver), low-dose (LD, $5.0 \times 10^{6} \mathrm{cell} / \mathrm{s} / \mathrm{kg}$ body weight), middle-dose (MD, $7.5 \times 10^{6} \mathrm{cells} / \mathrm{kg}$ body weight) and high-dose (HD, $10.0 \times 10^{6} \mathrm{cells} / \mathrm{kg}$ body weight). Injections were continuously performed 3 time at a 4 days interval based on: (a) mouse has a 4-5 days estrous cycle [37] and (b) transplanted hAMSCs live in mouse at least for 1 week after tail vein injection (our unpublished data). All experimental mice lived to the planed endpoints and humanely sacrificed before next step analysis on tissues and organs, except that there were 4 mice dead from operation accident (1 in NS group, 1 in MD group and 2 in HD group). After injection, hAMSCs were detected in ovary (Fig. 3a-d) and all tested organs (Fig. S1). Interestingly, except for ovary (resided in the mesenchyme) (Fig. 3A-D) and spleen (resided in the trabecular region) (Fig. S1C, c'), the transplanted hAMSCs did not showed special residence in other tested organs (Fig. S1). Meanwhile, co-expression human- specific gene STEM121 and MSCs specific surface marker of CD73 were observed in ovary (Fig. 3c, d). Our results showed that hAMSCs were homing in ovaries and at the same time maintained the characteristic of MSCs.

\section{hAMSCs transplantation positively changed hormone levels in AR-DOR mice}

The effect of hAMSCs transplantation on AMH, E2 and FSH hormone secretion in the serum of treatment mice were investigated. The result showed that the AMH level of MD group $(384.8 \pm 87.0 \mathrm{pg} / \mathrm{ml})$ was significantly increased compared to the NS $(220.1 \pm 78.3 \mathrm{pg} / \mathrm{ml}), \mathrm{HAS}(197.8 \pm 54.0 \mathrm{pg} / \mathrm{ml}), \mathrm{LD}(262.0 \pm$ $144.5 \mathrm{pg} / \mathrm{ml})$ and HD groups $(265.2 \pm 74.6 \mathrm{pg} / \mathrm{ml})(P<0.05)$, meanwhile of HD group was significantly higher than that of HSA group $(P<0.05)$ (Fig. $3 e)$. Additionally, the FSH level of the MD group $(2.5 \pm 1.1$ $\mathrm{mlU} / \mathrm{mL})$ were significantly decreased compared to the NS $(5.1 \pm 0.6 \mathrm{mlU} / \mathrm{mL}), \mathrm{HAS}(4.9 \pm 0.6 \mathrm{mlU} / \mathrm{mL})$ and $\mathrm{HD}$ groups $(4.4 \pm 0.8 \mathrm{mlU} / \mathrm{mL})(P<0.05)$, and of the $\mathrm{HD}$ group were significantly decreased compared to the NS group. However, though the E2 level of the MD group $(2.5 \pm 1.1 \mathrm{pg} / \mathrm{ml})$ showed an upward trend compared to the other groups, the difference is not statistically significant (Fig. 3e). These results demonstrated that hAMSCs transplantation positively changed the sex hormone levels in serum in ARDOR mice, in especial of middle dose $\left(7.5 \times 10^{6} \mathrm{cells} / \mathrm{kg}\right.$ body weight).

\section{hAMSCs transplantation increased the number of follicles in AR-DOR mice}

The effect of hAMSCs transplantation on the number of follicles at different developmental stages were evaluated. It was found that number of primordial follicles in HD group $(8.8 \pm 3.3)$ was significantly higher 
than that in NS $(5.8 \pm 2.4)$ and HSA $(5.6 \pm 2.5)$ groups $(P<0.05)$ (Fig. $3 F \& G)$, while there was no significant difference between the other four groups. Similarly, number of primary follicles in HD group $(8.3 \pm 3.7)$ was significantly higher than that in HSA $(5.3 \pm 2.0)$ and LD $(4.7 \pm 2.7)$ groups $(P<0.05)$ (Fig. 3F\&G), yet still there was no significant difference between the other four groups. Fundamentally, HD group showed the highest number of secondary $(20.3 \pm 6.7)$ and antral $(10.9 \pm 3.3)$ follicles and overwhelmed all the other groups $(P<0.05)(F i g .3 f, g)$, at the same time MD group had more secondary $(10.0 \pm 4.8$ vs $8.3 \pm 4.8)$ and antral $(5.0 \pm 3.2$ vs $2.7 \pm 2.4)$ follicles than $L D$ group $(P<0.05)$ and no significant difference was observed between other groups (Fig. 3f, g). Consistently, HD group (14.4 \pm 4.4 ) displayed a higher number of oocytes compare to the other groups (NS:10.9 \pm 4.3 ; HSA:12.0 \pm 3.1 ; LD: $11.1 \pm 5.1$; MD: $12.0 \pm 2.4$ ) though there is no statistical significance (Fig. 3h). Above results demonstrated middle and high-dose of hAMSCs transplantation promoted follicles development and the high-dose (1.0×107cells/kg body weight) showed the highest effects.

\section{hAMSCs transplantation improved the quality of oocytes in AR-DOR mice}

The effects of hAMSCs transplantation on the quality of oocyte were evaluated through observing the rates of 2-cell formation (2-cell embryos/retrieval oocytes), blastocyst formation (blastocyst embryos/2cell embryos) and gestation (pregnant mice with alive fetus/total mice), and the average alive fetus numbers in every pregnant mouse. The results showed that all dose groups had a higher 2-cell formation rate (LD: $69.7 \pm 19.4 \%$; MD:74.7 \pm 19.4\%; HD:73.2 $\pm 9.9 \%$ ) (Fig. 4a, C) and gestation rate (LD: $87.50 \%$ (7/8); MD: 85.71\% (6/7); HD: 83.33\% (5/6)) compared to the NS (2-cell formation rate: $52.5 \pm 37.0 \%$; embryo gestation rate: $57.14 \%(4 / 7)$ ) and HSA (2-cell formation rate: $52.5 \pm 37.0 \%$; gestation rate: $62.50 \%(5 / 8)$ ) groups (Fig. 4e), though there was no statistical significance. No surprisingly, significantly higher blastocyst formation rates were observed in the LD $(95.9 \pm 7.0 \%)$, MD $(96.3 \pm 4.0 \%)$ and HD $(95.1 \pm 3.5 \%)$ groups compare to NS $(73.9 \pm 4.2 \%)$ and HSA $(83.8 \pm 9.1 \%)$ groups $(P<0.05)$ (Fig. $4 b, d)$. Similarly, the HD group (10.2 \pm 1.3$)$ presented significantly higher average number of live fetus than the NS $(8.0 \pm 0.8)$, HSA $(8.2 \pm 2.0)$ and LD $(7.3 \pm 4.3)$ groups $(P<0.05)$, while there was no obvious difference observed between other groups (Fig. 4f). Our results demonstrated that hAMSCs transplantation enhanced the quality of oocyte and subsequent embryo development in AR-DOR mice, especially in the HD group.

\section{hAMSCs transplantation repressed apoptosis of ovarian cells in AR-DOR mice}

Apoptosis of supporting cells in ovary correlates with oocyte quality and subsequent embryo development [38]. The effects of hAMSCs transplantation on the apoptosis level in granulosa and stromal cells was estimated. Compared to the NS group $(20.53 \pm 2.64 \%)$, the rates of apoptosis in granulosa cells were decreased in the HSA (14.30 $\pm 2.18 \%), \operatorname{LD}(12.12 \pm 0.64 \%), \mathrm{MD}(7.04 \pm 0.46 \%)$ and HD $(6.65 \pm 0.47 \% /)$ groups $(P<0.05$, Fig. $5 a, b)$. Meanwhile, the MD and HD groups also showed significantly lower apoptosis levels compared to the HSA and LD group $(P<0.05)$ (Fig. 5a, b). However, there was no significant difference between the MD and HD groups, and between the HSA and LD groups 
(Fig. 5a, b). The apoptosis levels in stromal cells indicated similar results between different groups: HSA (13.21 $\pm 2.24 \%), \mathrm{LD}(11.72 \pm 0.63 \%), \mathrm{MD}(6.37 \pm 0.62 \%)$ and $\mathrm{HD}(5.02 \pm 0.12 \% /)$ groups all significantly lower than NS group $(20.51 \pm 2.88 \%), M D$ and HD groups significantly lower than HSA and LD groups, except for that HD group was further significantly lower than MD group (Fig. $5 a, b$ ). These results indicated that the hAMSCs transplantation reduced the apoptosis level of ovarian cells in AR-DOR mice, in manner of dose-dependent.

\section{hAMSCs transplantation enhanced Ampk/FoxO3a signaling pathway in the ovary of AR-DOR mice}

Aging ovaries are associated with an imbalanced redox state which increases reducing reactive oxygen species (ROS) relative to antioxidant signaling [39]. It is reported that FoxO3a is crucial for oocyte maturation and subsequent embryonic development through activating mitophagy, reducing ROS induced mitochondrial injury $[40,41]$. Here we tested if FoxO3a signaling participated in the ovarian function improvement after hAMSCs transplantation. We found that the expression of superoxide dismutase 2 (Sod2) (Fig. 6a), the ratio of phosphorylated FoxO3a ( $\mathrm{p}-\mathrm{FoxO3a})$ to total FoxO3a $(\mathrm{P}<0.05)$ (Fig. 6b) was increased. Consistently, the enhanced expression of FoxO3a in cytoplasm was observed (Fig. 6e). Additionally, expression level of Ampk, the catalyzer promoting FoxO3a phosphorylation, increased as well $(\mathrm{P}<0.05)$ (Fig. 6c). Interestingly, expression of Akt and phosphorylated Akt were not changed (Fig. 6d). Our results indicated that the oxidation resistance and Ampk/FoxO3a signaling pathway were both enhanced in the ovaries of AR-DOR mice after hAMSCs transplantation.

\section{Discussion}

There is a clear correlation between increasing maternal age and decreasing success in conceiving both spontaneously and after IVF $[42,43]$, which is attributed to the diminished ovarian reserve and decreased oocyte quality. Age is the independent factor crucially affects IVF outcomes [44]. IVF can not reverse the adverse impacts of advanced age (particularly in women over 40) though it can help part of younger women to have babies [45]. After IVF treatment, live birth rate is only $3.1 \%$ in women over 42 years old, while $46.8 \%$ in women under 35 , the same trend as parallels spontaneous conception rates [46]. Mature oocytes are developing from members of primordial follicle pool which is established in utero. Thus, depletion on primordial follicle pool and/or adverse microenvironment in the ovary can impede the maturing of oocyte [47-49]. Furthermore, aging-associated systems can also affect oocyte quality because the hypothalamus-pituitary-gonad (HPG) axis signaling synergistically regulate oocyte maturation [50].

Primordial follicle pool is declining irreversibly until menopause, but exceeding activation of primordial follicles asynchronous with age can result in POF, for example almost all of young women of cancer patient suffered POF after accepted radiation and chemotherapy [51-53]. The Pten/Akt/Fox03a pathway is crucial in regulating quiescence or activation of primordial follicles [54-58]. The FoxO3a and phosphorylation FoxO3a are the critical factors, usually FoxO3a represses while phosphorylation FoxO3a 
activates the development of primordial follicles. Additionally, Fox3a is also involved in mitophagy in aging oocytes [59]. Aging and many of the age-related diseases is tightly related to abnormal distribution and function of mitochondria [60]. While mitophagy is a major process to maintain normal quality and quantity of mitochondria in cells, especially in oocytes because they contain a large number of mitochondria to meet the demand of energy production during oocyte maturation and subsequent embryonic development [61]. There are also reports demonstrate that AMPK is the guardian of metabolism and mitochondrial homeostasis, crucial in the regulation of metabolism via AMPK/TSC/mTOR pathway and of mitophagy through AMPK/Fox03a signaling [62].

In the study an AR-DOR mouse model with ovarian function equivalent to 35 years old women [32] was established. Our results showed hAMSCs injection significantly improve the ovarian function of AR-DOR mice, meanwhile increased the expression of Ampk and the ratio of phosphorylation FoxO3a to FoxO3a (Fig. 6b, c), proposing that hAMSCs transplantation might improve ovarian function through enhancing mitophagy in oocyte. Furthermore, increased phosphorylation FoxO3a might simultaneously promote the activation of primordial follicles because the HD group had significantly higher numbers of follicles at all of the four development stages in AR-DOR mice (Fig. $3 \mathrm{f}, \mathrm{g}$ ). Aging can result in excess accumulation of ROS in ovary and impair oocytes maturation $[12,13]$. hAMSCs transplantation increased expression of antioxidative gene of Sod2 (Fig. 6a) meanwhile repressed apoptosis in granulosa and stromal cells (Fig. 5), demonstrating that hAMSCs might also promote oocyte maturation by improving ovarian microenvironment, consistent with previous reports $[24,25,29,30]$. Besides, serum hormone levels of ARDOR mice were rebalanced (Fig. 3e), implying that the HPG axis signaling was regulated too after hAMSCs transplantation. Interestingly, hAMSCs resided in ovaries but still presented the features of MSCs (Fig. 3c, d), meaning that they functioned by secreting cytokines [63] (Fig. 1b) and/or vesicles [24, 29] rather than differentiation into tissue-specific cells. That precise hAMSCs-secreting components effective in ovarian function repairability and the function mechanism would be explored in future research.

It should be pay more attention to the dose in cell therapy because in our study a relatively small difference (about 30\%) in dosage had shown significant difference on therapeutic effects (Fig. 3, 4). In view of the size, potential immunogenicity of transplanted cells and they would live in recipient body for a relatively long time, an effective and safe does as low as possible is recommended in future clinical application.

Furthermore, ovarian function extremely damaged would not be recovered by hAMSCs transplantation. We tested the limitation of cell therapy by an X-ray induced POF mouse model. The ovaries of POF mice were smaller and follicles were decreased significantly than that of young controls (YC) (Fig. S2a), even no antral follicle was observed in the ovaries (Fig. S2b). After hAMSCs transplantation, though the serum levels of AMH, E2 and FSH were changed significantly (Fig. S2c), in ovary severe fibrillation was ameliorated (Fig. S2e) and primordial follicles were activated, yet no antral follicle was detected in POF mice (Fig. S2d). Our results suggests that in future clinical application, ovarian function of patients should be carefully evaluated before cell transplantation. 


\section{Conclusion}

HAMSCs transplantation via tail vein promotes follicles activation, oocyte maturation and subsequent embryonic development in AR-DOR mice. The transplanted hAMSCs are homing in ovary meanwhile maintain the characterization of MSCs, effecting by cell secretion to activated AMPK/FoxO3a signaling and downstream antioxidation pathway. Although the underlying mechanism is unclear yet, hAMSCs transplantation might promise a prospect candidate treatment for AR-DOR therapy.

\section{Abbreviations}

ANG-1: Angiopoietin-1; ADSCs: adipose derived stem cells; AFC: antral follicle counting; AMH: antiMullerian hormone; AR-DOR: age-related Diminished Ovarian Reserve; ART: artificial assisted reproduction; DOR: Diminished Ovarian Reserve; E2: estradiol; ELISA: enzyme linked immunosorbent assay; FGF7: fibroblast growth factor 7; FSH: Follicle-stimulating hormone; hAMSC: Human amnionderived mesenchymal stem cell; HRP: horseradish peroxidase; HSA: human serum albumin; HuMenSCs: human endomentrial stem cells; IL-6: Interleukin- 6; MSCs: mesenchymal stem cells; NS: normal saline; POF: premature ovarian failure; PVDF: polyvinyl fluoride; ROS: reactive oxygen species; SDS-PAGE: Sodium dodecyl sulfate polyacrylamide gel electrophoresis; Sod2: Superoxide dismutase 2; UCMSCs: human umbilical cord mesenchymal stem cells.

\section{Declarations}

\section{Acknowledgements}

All authors are acknowledged for their contribution to the study.

\section{Authors' contributions}

L. Qin and J. liu were responsible for experimental design, literature research, data analysis and interpretation, and manuscript composing. H. Liu and C. Jiang were in charge of all experimental studies and deeply participated in literature research, data analysis and interpretation, and manuscript composing. M. Cao, B. La and Y. Zhang participated in animal experiments. S. Ning and J. Zhou were responsible for preparation of AMSCs. C. Li and H. Wu were responsibly quality control on AMSCs. Z. Yan, J. Zhou and Y. Cui were responsible for oocyte counting, in vitro fertilization and embryo culture. Ma, M. Wang and Li Chen were responsible for collect donations of human amnion.

\section{Funding}

This work was supported by the grants from the National Natural Science Foundation of China (81730041, 81671447), the State Key Laboratory of Reproductive Medicine Program (SKLRM-GC201803), the National Key Research and Development Program of China (2017YFC1001303), the Program of 
Jiangsu Province Clinical Medical Center (YXZXB2016001, BL2012009), the Program of Jiangsu Commission of Health (H201605).

\section{Availability of data and materials}

All data generated and/or analyzed during this study are included in this published article.

\section{Ethics approval and consent to participate}

All animal experiments were approved by the Institutional Animal Care and Use Committee (IACUC 1808004) of Nanjing Medical University in Jiangsu, China. Also, the collection of human amniotic membrane and their use were conducted under the guidelines and with the approval of the first affiliated hospital with Nanjing medical university (2012-SR-128). All patients provided written informed consent to the respective use of their tissues.

\section{Consent for publication}

Not applicable.

\section{Competing interests}

The authors declare no conflicts of interest.

\section{Author details}

${ }^{1}$ State Key Laboratory of Reproductive Medicine, Center of Clinical Reproductive Medicine, First Affiliated Hospital, Nanjing Medical University, Nanjing 210029, China.

${ }^{2}$ Department of Obstetrics, First Affiliated Hospital, Nanjing Medical University, Nanjing 210029, China.

\section{References}

1. Devine, S.L. Mumford, M. Wu, A.H. DeCherney, M.J. Hill, A. Propst, Diminished ovarian reserve in the United States assisted reproductive technology population: diagnostic trends among 181,536 cycles from the Society for Assisted Reproductive Technology Clinic Outcomes Reporting System, Fertil Steril, 104 (2015) 612-19 e3.

2. Nikolaou, A. Templeton, Early ovarian ageing: a hypothesis. Detection and clinical relevance, Hum Reprod, 18 (2003) 1137-9.

3. J. Levi, M.F. Raynault, P.A. Bergh, M.R. Drews, B.T. Miller, R.T. Scott, Jr., Reproductive outcome in patients with diminished ovarian reserve, Fertil Steril, 76 (2001) 666-9.

4. S.o.R.M. (CSRM), Chinese practice guideline on the assisted reproductive technology (ART) strategies for women with advanced age, Chinese Journal of Evidence-Based Medicine, 19 (2019) 253-70. 
5. G. Reed, S.N. Babayev, O. Bukulmez, Shifting paradigms in diminished ovarian reserve and advanced reproductive age in assisted reproduction: customization instead of conformity, Semin Reprod Med, 33 (2015) 169-78.

6. F. Kawwass, H.S. Hipp, D.R. Session, D.M. Kissin, D.J. Jamieson, A.R.T.S.S.G. National, Severity of Diminished Ovarian Reserve and Chance of Success with Assisted Reproductive Technology, J Reprod Med, 62 (2017) 153-60.

7. M. Musters, M. van Wely, S. Mastenbroek, E.M. Kaaijk, S. Repping, F. van der Veen, M.H. Mochtar, The effect of recombinant LH on embryo quality: a randomized controlled trial in women with poor ovarian reserve, Hum Reprod, 27 (2012) 244-50.

8. J. Norman, H. Alvino, L.M. Hull, B.W. Mol, R.J. Hart, T.L. Kelly, L. Rombauts, L. investigators, Human growth hormone for poor responders: a randomized placebo-controlled trial provides no evidence for improved live birth rate, Reprod Biomed Online, 38 (2019) 908-15.

9. Xu, V. Nisenblat, C. Lu, R. Li, J. Qiao, X. Zhen, S. Wang, Pretreatment with coenzyme Q10 improves ovarian response and embryo quality in low-prognosis young women with decreased ovarian reserve: a randomized controlled trial, Reprod Biol Endocrinol, 16 (2018) 29.

10. Feichtinger, E.R. Barnea, A. Nyachieo, M. Brannstrom, S.S. Kim, Allogeneic ovarian transplantation using immunomodulator preimplantation factor (PIF) as monotherapy restored ovarian function in olive baboon, J Assist Reprod Genet, 35 (2018) 81-89.

11. Klopstock, B. Klopstock, H. Prokisch, Mitochondrial replacement approaches: challenges for clinical implementation, Genome Med, 8 (2016) 126.

12. Luti, T. Fiaschi, F. Magherini, P.A. Modesti, P. Piomboni, L. Governini, A. Luddi, A. Amoresano, A. Illiano, G. Pinto, A. Modesti, T. Gamberi, Relationship between the metabolic and lipid profile in follicular fluid of women undergoing in vitro fertilization, Mol Reprod Dev, 87 (2020) 986-97.

13. Seli, T. Wang, T.L. Horvath, Mitochondrial unfolded protein response: a stress response with implications for fertility and reproductive aging, Fertil Steril, 111 (2019) 197-204.

14. A.M. Hoque, T. Umehara, T. Kawai, M. Shimada, Adverse effect of superoxide-induced mitochondrial damage in granulosa cells on follicular development in mouse ovaries, Free Radic Biol Med, 163 (2020) 344-55.

15. Yan, D. Deng, Y. Wu, K. Wu, J. Qu, F. Li, Catalpol protects rat ovarian granulosa cells against oxidative stress and apoptosis through modulating the PI3K/Akt/mTOR signaling pathway, Biosci Rep, 40 (2020).

16. Rodriguez-Varela, E. Labarta, Clinical Application of Antioxidants to Improve Human Oocyte Mitochondrial Function: A Review, Antioxidants (Basel), 9 (2020).

17. Cho, T.H. Kim, J. Seok, J.H. Jun, H. Park, M. Kweon, J.Y. Lim, G.J. Kim, Vascular remodeling by placenta-derived mesenchymal stem cells restores ovarian function in ovariectomized rat model via the VEGF pathway, Lab Invest, (2020).

18. Wang, L. Yu, M. Sun, S. Mu, C. Wang, D. Wang, Y. Yao, The therapeutic potential of umbilical cord mesenchymal stem cells in mice premature ovarian failure, Biomed Res Int, 2013 (2013) 690491. 
19. Yan, Y. Wu, L. Li, J. Wu, F. Zhao, Z. Gao, W. Liu, T. Li, Y. Fan, J. Hao, J. Liu, H. Wang, Clinical analysis of human umbilical cord mesenchymal stem cell allotransplantation in patients with premature ovarian insufficiency, Cell Prolif, 53 (2020) e12938.

20. Su, L. Ding, J. Cheng, J. Yang, X. Li, G. Yan, H. Sun, J. Dai, Y. Hu, Transplantation of adipose-derived stem cells combined with collagen scaffolds restores ovarian function in a rat model of premature ovarian insufficiency, Hum Reprod, 31 (2016) 1075-86.

21. Sun, S. Wang, Y. Li, L. Yu, F. Gu, C. Wang, Y. Yao, Adipose-derived stem cells improved mouse ovary function after chemotherapy-induced ovary failure, Stem Cell Res Ther, 4 (2013) 80.

22. E. Tomaszewski, E. Constance, M.M. Lemke, H. Zhou, V. Padmanabhan, K.B. Arnold, A. Shikanov, Adipose-derived stem cell-secreted factors promote early stage follicle development in a biomimetic matrix, Biomater Sci, 7 (2019) 571-80.

23. Ding, G. Yan, B. Wang, L. Xu, Y. Gu, T. Ru, X. Cui, L. Lei, J. Liu, X. Sheng, B. Wang, C. Zhang, Y. Yang, R. Jiang, J. Zhou, N. Kong, F. Lu, H. Zhou, Y. Zhao, B. Chen, Y. Hu, J. Dai, H. Sun, Transplantation of UCMSCs on collagen scaffold activates follicles in dormant ovaries of POF patients with long history of infertility, Sci China Life Sci, 61 (2018) 1554-65.

24. Ding, L. Zhu, H. Shen, J. Lu, Q. Zou, C. Huang, H. Li, B. Huang, Exosomal miRNA-17-5p derived from human umbilical cord mesenchymal stem cells improves ovarian function in premature ovarian insufficiency by regulating SIRT7, Stem Cells, 38 (2020) 1137-48.

25. H. Choi, J. Seok, S.M. Lim, T.H. Kim, G.J. Kim, Microenvironmental changes induced by placentaderived mesenchymal stem cells restore ovarian function in ovariectomized rats via activation of the PI3K-FOX03 pathway, Stem Cell Res Ther, 11 (2020) 486.

26. A.-q. ZHANG Qin-jing, NING Song, GAO Chao, JIANG Chun-yan, CUI Yu-gui, CHEN Juan, QIN Lian-ju, LIU Jia-yin., Expressions of secretory factors in different types of stem cells, Journal Of Reproductive Medicin, 25 (2016) 528-39.

27. Wu, T. Fang, H. Lang, M. Chen, P. Shi, X. Pang, G. Qi, Comparison of the proliferation, migration and angiogenic properties of human amniotic epithelial and mesenchymal stem cells and their effects on endothelial cells, Int J Mol Med, 39 (2017) 918-26.

28. Feng, L. Ling, W. Zhang, X. Liu, Y. Wang, Y. Luo, Z. Xiong, Effects of Human Amnion-Derived Mesenchymal Stem Cell (hAD-MSC) Transplantation In Situ on Primary Ovarian Insufficiency in SD Rats, Reprod Sci, 27 (2020) 1502-12.

29. Ding, C. Qian, S. Hou, J. Lu, Q. Zou, H. Li, B. Huang, Exosomal miRNA-320a Is Released from hAMSCs and Regulates SIRT4 to Prevent Reactive Oxygen Species Generation in POI, Mol Ther Nucleic Acids, 21 (2020) 37-50.

30. Liu, X. Zhang, Z. Fan, Y. Wang, G. Yao, X. Wan, Z. Liu, B. Yang, L. Yu, Human amniotic mesenchymal stem cells improve the follicular microenvironment to recover ovarian function in premature ovarian failure mice, Stem Cell Res Ther, 10 (2019) 299.

31. Alviano, V. Fossati, C. Marchionni, M. Arpinati, L. Bonsi, M. Franchina, G. Lanzoni, S. Cantoni, C. Cavallini, F. Bianchi, P. Tazzari, G. Pasquinelli, L. Foroni, C. Ventura, A. Grossi, G. Bagnara, BMC 
Developmental Biology, 7 (2007).

32. Liu, Q. Fan, G. Yang, L. Wang, Proteomic profiling of aging in glomeruli of mice by using twodimensional differential gel electrophoresis, Med Sci Monit, 21 (2015) 419-25.

33. Cruz, D. Fernandois, A.H. Paredes, Ovarian function and reproductive senescence in the rat: role of ovarian sympathetic innervation, Reproduction, 153 (2017) R59-R68.

34. Wang, C. Zhong, R. Yang, Y. Yin, R. Tan, L. Gao, C. Gao, Y. Cui, D. Pu, J. Wu, Hfm1 participates in Golgi-associated spindle assembly and division in mouse oocyte meiosis, Cell Death Dis, 11 (2020) 490.

35. Kunishige, N. Kawate, T. Inaba, H. Tamada, Exposure to Zearalenone During Early Pregnancy Causes Estrogenic Multitoxic Effects in Mice, Reprod Sci, 24 (2017) 421-27.

36. D. Fernandez, G.S. Fernandes, A.P. Favareto, J.E. Perobelli, M. Sanabria, W.D. Kempinas, Decreased Implantation Number After In Utero Artificial Insemination Can Reflect an Impairment of Fertility in Adult Male Rats After Exogenous Leptin Exposure, Reprod Sci, 24 (2017) 234-41.

37. C. Cora, L. Kooistra, G. Travlos, Vaginal Cytology of the Laboratory Rat and Mouse: Review and Criteria for the Staging of the Estrous Cycle Using Stained Vaginal Smears, Toxicol Pathol, 43 (2015) 776-93.

38. Fan, Y. Chang, L. Wei, J. Chen, J. Li, S. Goldsmith, S. Silber, X. Liang, Apoptosis of mural granulosa cells is increased in women with diminished ovarian reserve, J Assist Reprod Genet, 36 (2019) 122535 .

39. J. Tarin, Potential effects of age-associated oxidative stress on mammalian oocytes/embryos, Mol Hum Reprod, 2 (1996) 717-24.

40. C. Ferber, B. Peck, O. Delpuech, G.P. Bell, P. East, A. Schulze, FoxO3a regulates reactive oxygen metabolism by inhibiting mitochondrial gene expression, Cell Death Differ, 19 (2012) 968-79.

41. Nasimian, P. Farzaneh, F. Tamanoi, S.Z. Bathaie, Cytosolic and mitochondrial ROS production resulted in apoptosis induction in breast cancer cells treated with Crocin: The role of FoxO3a, PTEN and AKT signaling, Biochem Pharmacol, 177 (2020) 113999.

42. J. Heffner, Advanced maternal age-how old is too old?, N Engl J Med, 351 (2004) 1927-9.

43. M. Nelson, D.A. Lawlor, Predicting live birth, preterm delivery, and low birth weight in infants born from in vitro fertilisation: a prospective study of 144,018 treatment cycles, PLoS Med, 8 (2011) e1000386.

44. (2017). 2015 Assisted Reproductive Technology. Retrieved from https://www.cdc.gov/art/reports/2015/national-summary-figures.html:

45. A. Malizia, M.R. Hacker, A.S. Penzias, Cumulative live-birth rates after in vitro fertilization, N Engl J Med, 360 (2009) 236-43.

46. (2019). 2017 Assisted Reproductive Technology. Retrieved from https://www.cdc.gov/art/reports/2017/fertility-clinic.html: 
47. Reddy, L. Liu, D. Adhikari, K. Jagarlamudi, S. Rajareddy, Y. Shen, C. Du, W. Tang, T. Hamalainen, S.L. Peng, Z.J. Lan, A.J. Cooney, I. Huhtaniemi, K. Liu, Oocyte-specific deletion of Pten causes premature activation of the primordial follicle pool, Science, 319 (2008) 611-3.

48. L. Leroy, D. Rizos, R. Sturmey, P. Bossaert, A. Gutierrez-Adan, V. Van Hoeck, S. Valckx, P.E. Bols, Intrafollicular conditions as a major link between maternal metabolism and oocyte quality: a focus on dairy cow fertility, Reprod Fertil Dev, 24 (2011) 1-12.

49. Zhang, W. Shen, M. De Felici, X.F. Zhang, Di(2-ethylhexyl)phthalate: Adverse effects on folliculogenesis that cannot be neglected, Environ Mol Mutagen, 57 (2016) 579-88.

50. W. Brann, V.B. Mahesh, The aging reproductive neuroendocrine axis, Steroids, 70 (2005) 273-83.

51. Sonigo, I. Beau, M. Grynberg, N. Binart, AMH prevents primordial ovarian follicle loss and fertility alteration in cyclophosphamide-treated mice, FASEB J, 33 (2019) 1278-87.

52. Mazaud, C.J. Guigon, A. Lozach, N. Coudouel, M.G. Forest, H. Coffigny, S. Magre, Establishment of the reproductive function and transient fertility of female rats lacking primordial follicle stock after fetal gamma-irradiation, Endocrinology, 143 (2002) 4775-87.

53. Meirow, D. Nugent, The effects of radiotherapy and chemotherapy on female reproduction, Hum Reprod Update, 7 (2001) 535-43.

54. Wu, Z. Zhang, X. Liao, L. Qi, Y. Liu, Z. Wang, Effect of high-fat diet-induced obesity on the Akt/FoxO/Smad signaling pathway and the follicular development of the mouse ovary, Mol Med Rep, 14 (2016) 3894-900.

55. Jang, O.H. Lee, Y. Lee, H. Yoon, E.M. Chang, M. Park, J.W. Lee, K. Hong, J.O. Kim, N.K. Kim, J.J. Ko, D.R. Lee, T.K. Yoon, W.S. Lee, Y. Choi, Melatonin prevents cisplatin-induced primordial follicle loss via suppression of PTEN/AKT/FoxO3a pathway activation in the mouse ovary, J Pineal Res, 60 (2016) 336-47.

56. Kawamura, Y. Cheng, N. Suzuki, M. Deguchi, Y. Sato, S. Takae, C.H. Ho, N. Kawamura, M. Tamura, S. Hashimoto, Y. Sugishita, Y. Morimoto, Y. Hosoi, N. Yoshioka, B. Ishizuka, A.J. Hsueh, Hippo signaling disruption and Akt stimulation of ovarian follicles for infertility treatment, Proc Natl Acad Sci U S A, 110 (2013) 17474-9.

57. Lins, B.B. Gouveia, R.S. Barberino, R.L.S. Silva, A.P.O. Monte, J.G.C. Pinto, D.S.P. Campinho, R.C. Palheta, M.H.T. Matos, Rutin prevents cisplatin-induced ovarian damage via antioxidant activity and regulation of PTEN and Fox03a phosphorylation in mouse model, Reprod Toxicol, 98 (2020) 209-17.

58. Llarena, C. Hine, Reproductive Longevity and Aging: Geroscience Approaches to Maintain Long-Term Ovarian Fitness, J Gerontol A Biol Sci Med Sci, (2020).

59. Zhou, Z. Xue, H.N. He, X. Liu, S.Y. Yin, D.Y. Wu, X. Zhang, H. Schatten, Y.L. Miao, Resveratrol delays postovulatory aging of mouse oocytes through activating mitophagy, Aging (Albany NY), 11 (2019) 11504-19.

60. Markaki, K. Palikaras, N. Tavernarakis, Novel Insights Into the Anti-aging Role of Mitophagy, Int Rev Cell Mol Biol, 340 (2018) 169-208. 
61. Wei, L. Liu, Q. Chen, Selective removal of mitochondria via mitophagy: distinct pathways for different mitochondrial stresses, Biochim Biophys Acta, 1853 (2015) 2784-90.

62. Herzig, R.J. Shaw, AMPK: guardian of metabolism and mitochondrial homeostasis, Nat Rev Mol Cell Biol, 19 (2018) 121-35.

63. Fu, Y. He, C. Xie, W. Liu, Bone marrow mesenchymal stem cell transplantation improves ovarian function and structure in rats with chemotherapy-induced ovarian damage, Cytotherapy, 10 (2008) $353-63$.

\section{Figures}


a

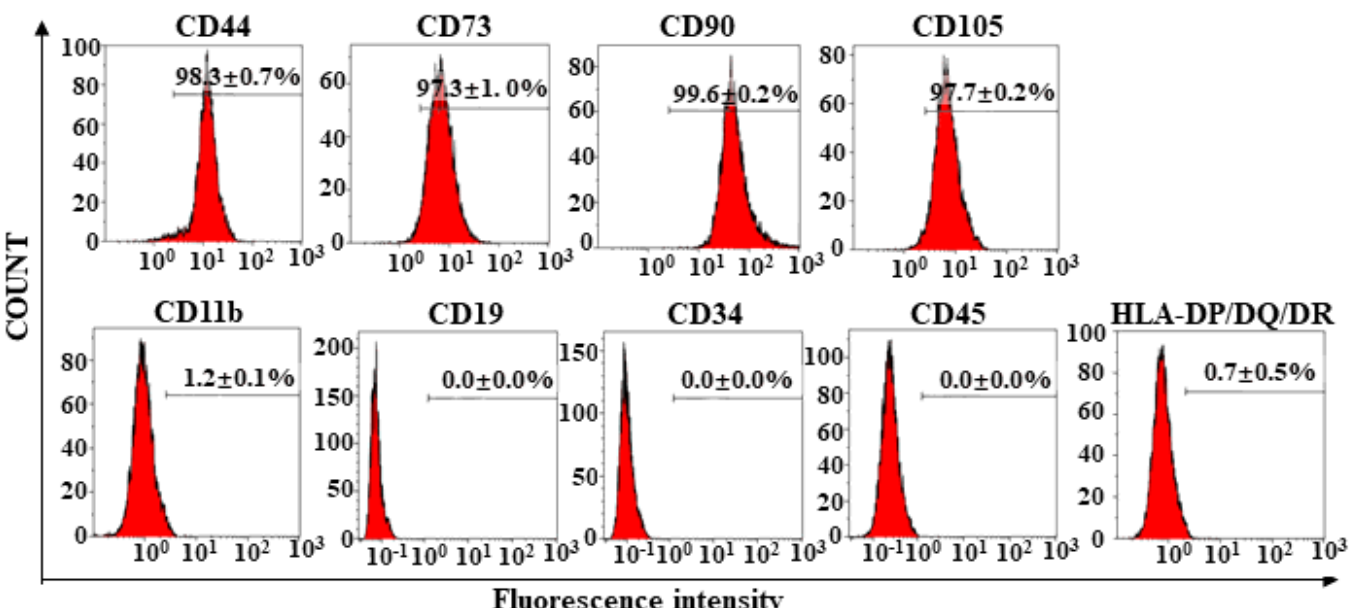

b

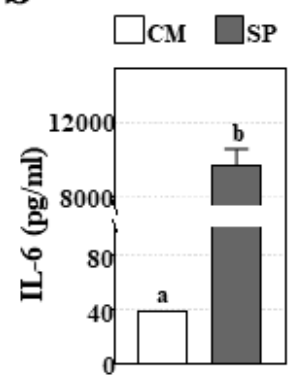

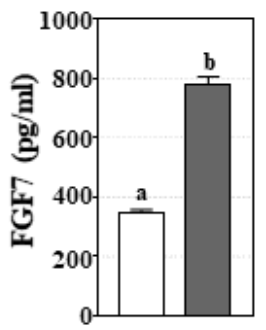

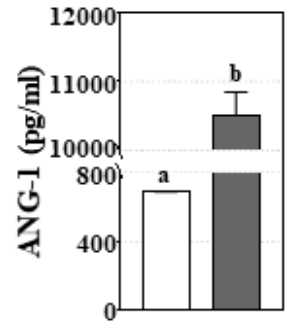

c

\begin{tabular}{ll}
\hline $\begin{array}{c}\text { Inspection } \\
\text { items }\end{array}$ & Results \\
\hline Cell viability & $96.6 \pm 0.6 \%$ \\
$\begin{array}{l}\text { Endotoxin } \\
\text { concentration }\end{array}$ & $<0.5 \mathrm{EU} / \mathrm{ml}$ \\
$\begin{array}{l}\text { Mycoplasma } \\
\text { infection }\end{array}$ & Negative \\
\hline
\end{tabular}

\section{Figure 1}

Quality control on hAMSCs a The expression of MSCs specific surface makers were analyzed by flow cytometry to identify hAMSCs. Cells expressed high level (>95\%) of CD73, CD44, CD105, CD90, were negative or expressed very low level (<2\%) of CD11b, CD19, CD34, CD45 and HLA-DP/DQ/DR. b Concentration of secreting cytokines were evaluated by enzyme-linked immunosorbent assays in the cell culture supernatant (SP) and complete cell culture media (CM). Significant high concentrations of IL-6, 
FGF7 and ANG-1 were detected in culture supernatant (SP). c hAMSCs viability, bacteria contamination and mycoplasma infection were tested by living cell counting, endotoxin detection and real-time fluorescence quantitative polymerase chain reaction, respectively. hAMSCs showed a high viability (96.6 $\pm 0.6 \%)$, negative bacteria contamination and mycoplasma infection. Experiments repeated at least for 3 times. Error bars indicate SEM. Different lowercase letters represent the significantly statistical differences $(P<0.05)$.

\section{$\mathbf{a}$}
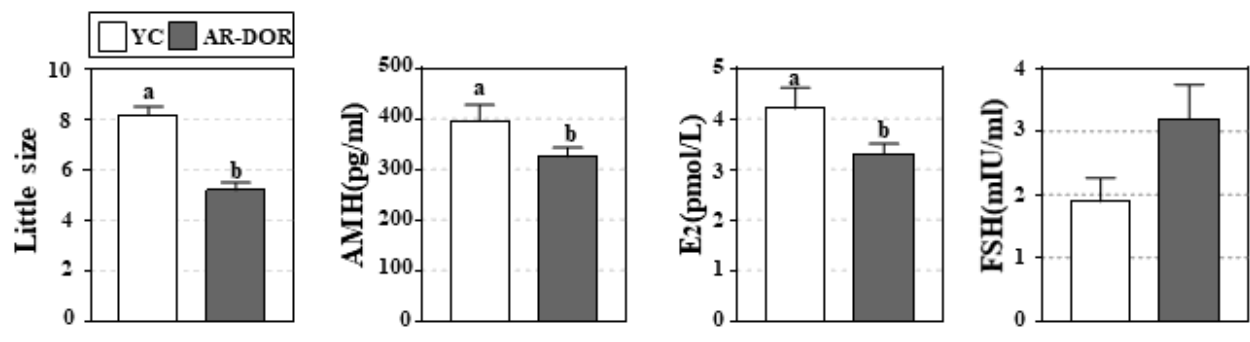

b
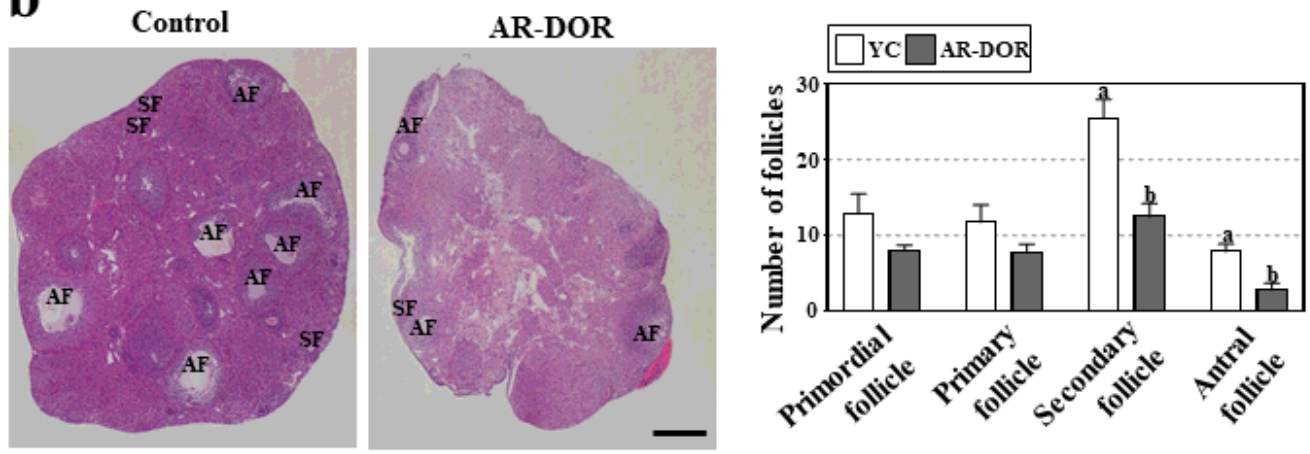

Figure 2 
Establishment of age-related diminished ovarian reserve (AR-DOR) mouse model a The Litter size, serum level of hormones (by ELISA kit) were analyzed to access ovarian function. The litter size and levels of AMH and E2 were significant decreased in AR-DOR mice and the level of FSH was increased in AR-DOR mice. b Histological analysis of paraffin-embedded sections and hematoxylin and eosin (HE) staining on mouse ovaries. The number of secondary and antral follicles were significant decreased in AR-DOR mice. AMH: anti-Mullerian hormone; E2: estradiol; FSH: follicle stimulating hormone. AF: antral follicle; SF: secondary follicle. Scar bar: $500 \mu \mathrm{m}$. $n=8$. Error bars indicate SEM. Different lowercase letters represent significantly statistical differences $(P<0.05)$. 

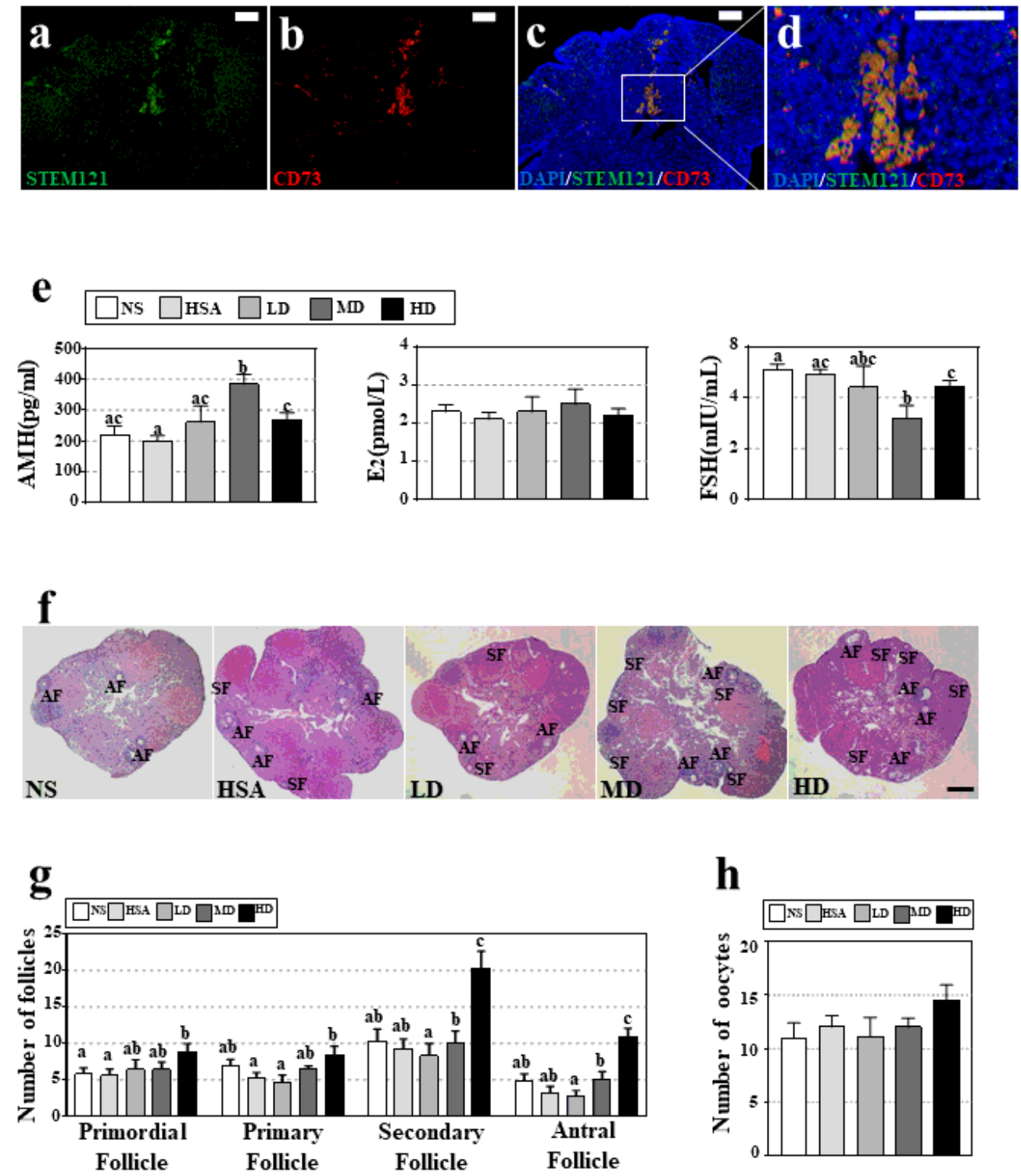

\section{Figure 3}

hAMSCs were homing in ovary and improved reproductive function after transplantation a-d hAMSCs homing and differentiation were traced by immunofluorescence experiments. Human specific antibody of STEM121 (green signal) and mesenchymal stem cells specific surface marker of CD73 (red signal) colocalization in the ovary. The sections were from middle-dose of hAMSCs transplanted ovary. Blue signal:

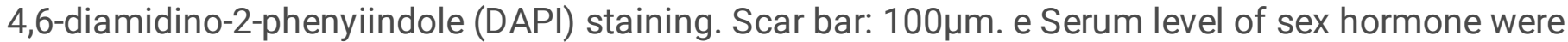


analyzed by ELISA kit. The AMH level was significantly increased and the FSH level was significantly decrease in MD group. $f$ Histological analysis of hematoxylin and eosin (HE) staining was performed to observe ovary. There were more follicles in MD and HD group. Scar bar, 500 $\mu \mathrm{m}$. g Follicle counting showed number of primordial and primary follicles in HD group, secondary and antral follicles in MD and HD group were significantly increased. h Retrieval oocyte counting indicated there was no significant difference in numbers of oocyte between different groups. All above assays were performed at day 7 post-transplantation of hAMSCs. AMH: anti-Mullerian hormone; E2: estradiol; FSH: follicle stimulating hormone. NS: normal saline group; HSA: $1 \%$ human serum albumin group; LD: low-dose group; MD: middle-dose group; HD: high-dose group. $n=8$. error bars indicate SEM; Different lowercase letters represent significantly statistical differences $(P<0.05)$. 

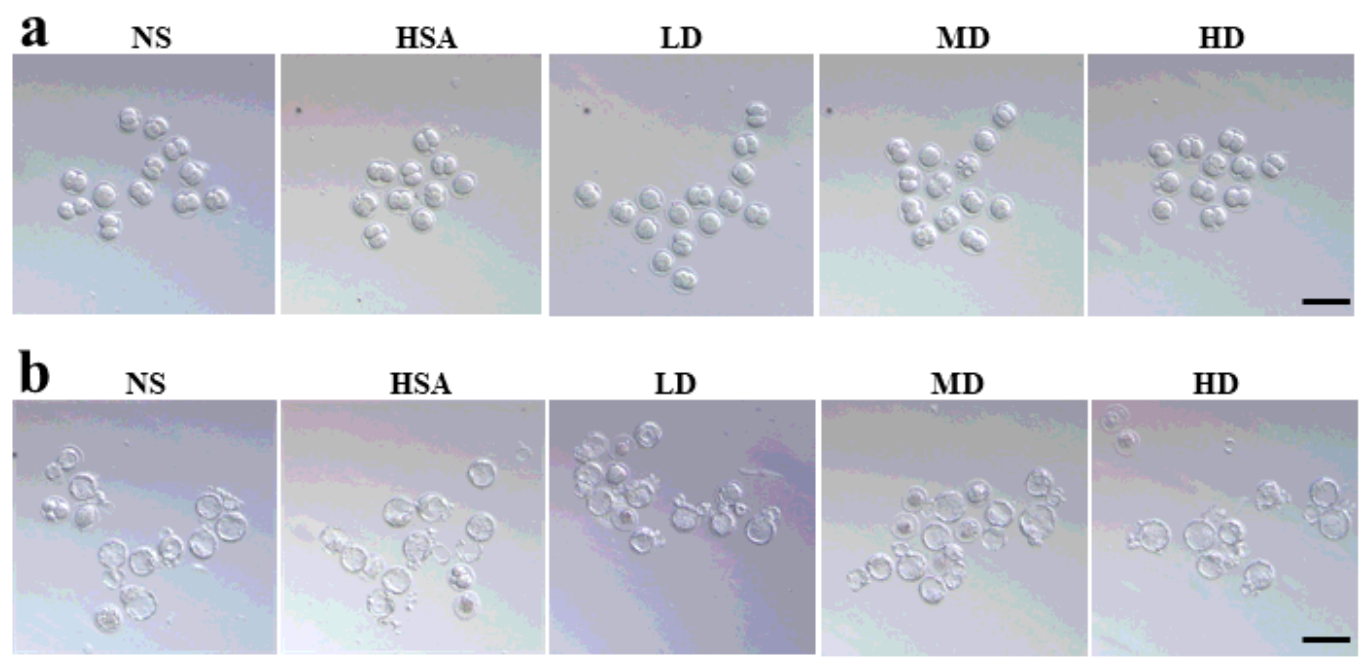

HSA

LD

MD

HD
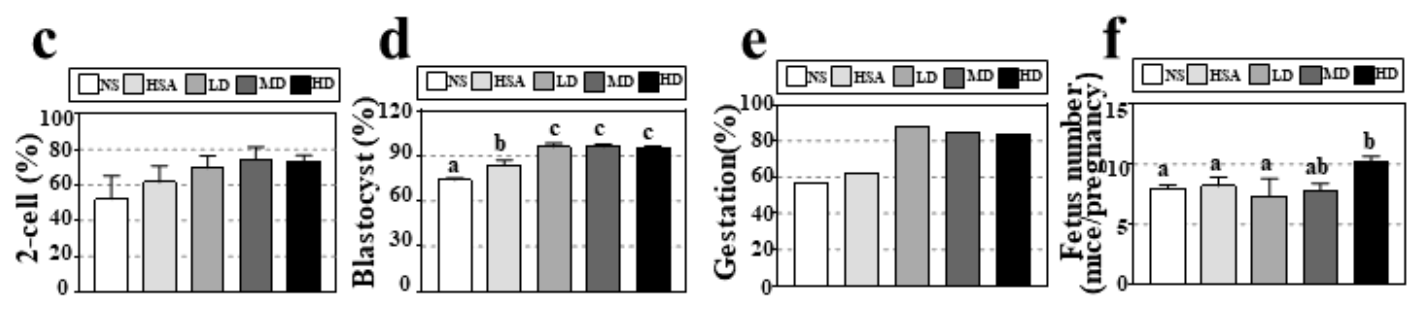

\section{Figure 4}

hAMSCs transplantation improved oocyte quality and subsequent embryo development a Morphology of 2-cell embryos. On the second day after fertilization, the zygote in the zona pellucida mitosis into 2 cells, no obvious difference was observed between groups under microscope. Scar bar: $200 \mu \mathrm{m}$. b Morphology of blastocysts. On the fifth day after fertilization, the zygote mitosis develops into a blastocyst which forming a cyst cavity and/or breaking through the zona pellucida, no obvious difference was observed 
between groups under microscope. Scar bar: $200 \mu \mathrm{m}$. c The rates of 2-cell formation (2-cell embryos/retrieval oocytes) were evaluated in groups and they were increased in LD, MD and HD groups. $\mathrm{n}=8$. $\mathrm{d}$ Rates of blastocyst formation (blastocyst embryos/2-cell embryos) were evaluated in groups and they were significantly increased in LD, MD and HD groups. $n=8$. e The rates of gestation (pregnant mice with live fetus/total mice) were evaluated in groups and they were increased in LD, MD and HD groups. $f$ Numbers of average live fetus were evaluated in groups. HD group had significantly higher number of live fetus. The number of mice analyzed in e and $f$ was $7,8,8,7$ and 6 , respectively for NS, HSA, LD, MD and HD group. Assay on 2-cell formation $(a, c)$ and blastocyst formation $(b, d)$ were performed at day 7 posttransplantation of hAMSCs. Assay on gestation (e) and live fetus ( $f$ ) were performed about at day 15 post-transplantation of hAMSCs. NS: normal saline group; HSA: $1 \%$ human serum albumin group; LD: low-dose group; MD: middle-dose group; HD: high-dose group. Error bars indicate SEM. Different lowercase letters represent significantly statistical differences $(P<0.05)$. 

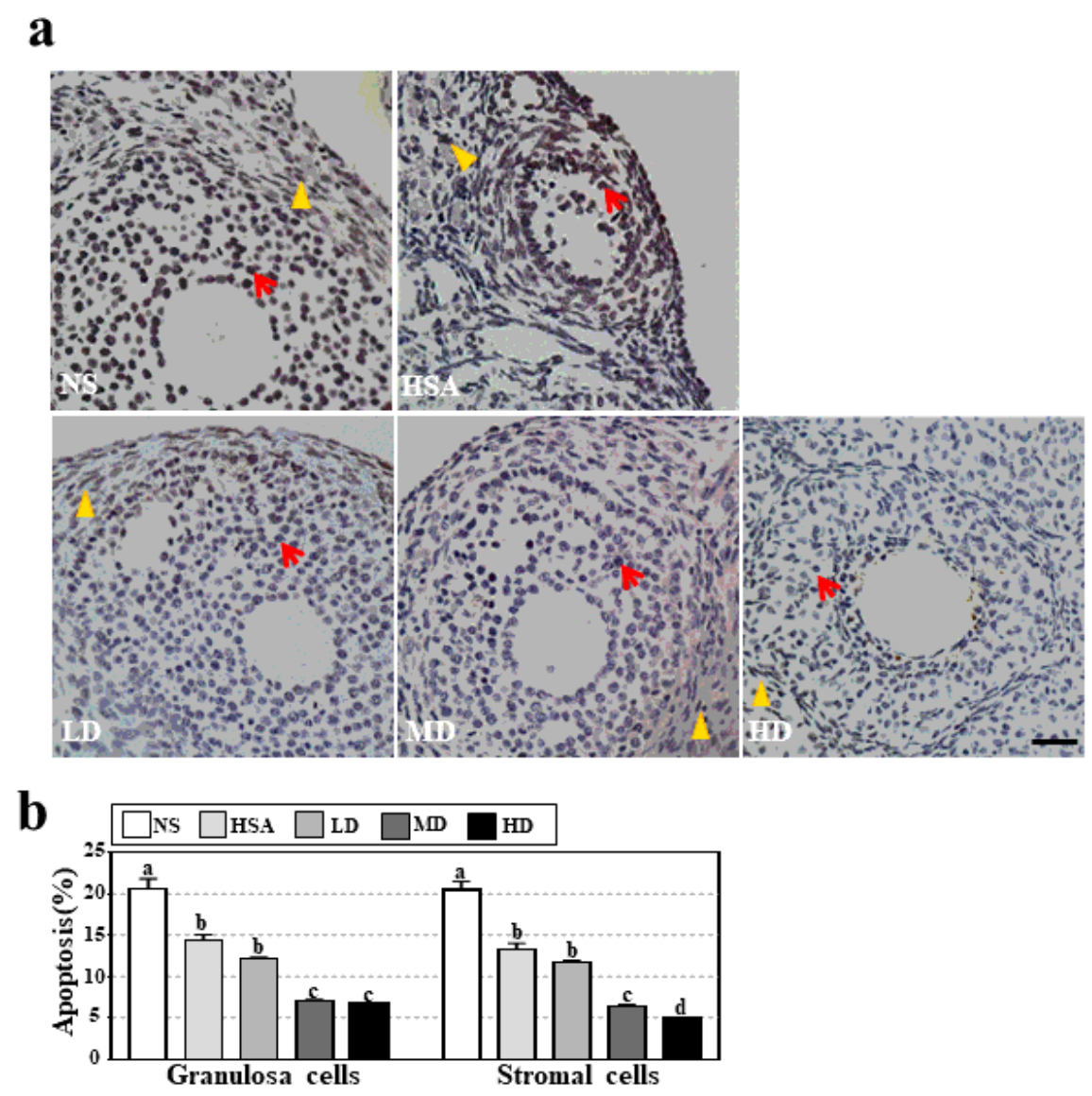

\section{Figure 5}

hAMSCs transplantation repressed apoptosis of ovarian cells in AR-DOR mice a Histological analysis on mouse ovary was carried out by TUNEL assay and microscope observation. Less apoptotic granulosa and stromal cells were observed in hAMSCs transplanted groups (LD, MD and HD). Triangles indicate apoptotic granulosa cells. Arrows indicate apoptotic stromal cells. b Apoptosis rate of granulosa cells and stromal cells were calculated in groups. The rate of apoptosis in granulosa and stromal cells were 
significantly decreased in MD and HD groups. NS: normal saline group; HSA: $1 \%$ human serum albumin group; LD: low-dose group; MD; middle-dose group; HD: high-dose group. Scar bar: $100 \mu \mathrm{m} . \mathrm{n}=8$. error bars indicate SEM. Different lowercase letters represent significantly statistical differences $(P<0.05)$.
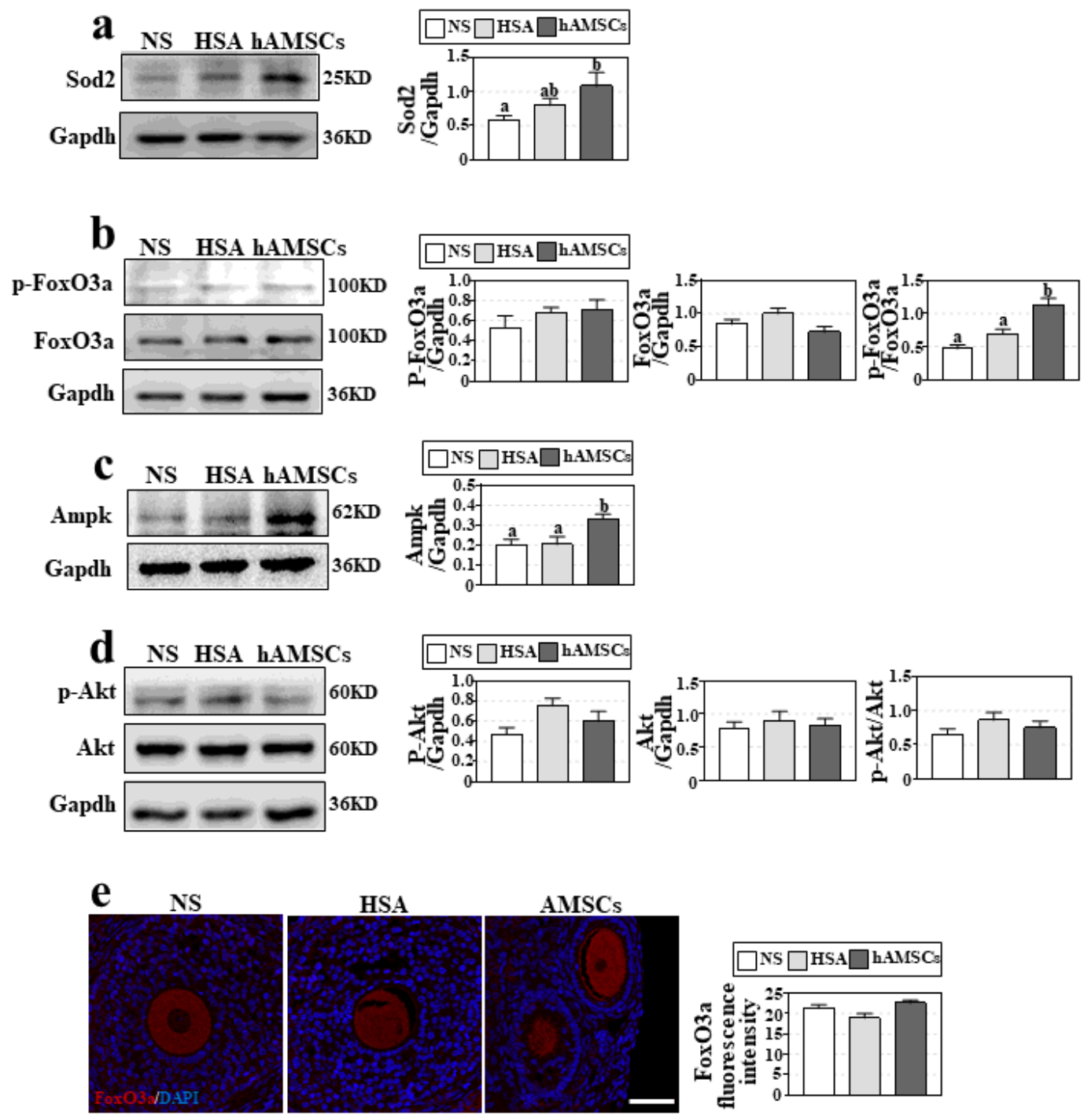

Figure 6

hAMSCs transplantation enhanced oxidation resistance and promoted Ampk/FoxO3a signaling in ovary of AR-DOR mice. a-d Expression level of proteins in mouse ovary were determined by Western blot 
analysis. a The expression of antioxidative Sod2 was increased in hAMSCs group. b The expression level of p-FoxO3a and FoxO3a in hAMSCs group was similar as that of NS and HSA groups, but ratio of pFoxO3a/FoxO3a was significantly improved in hAMSCs group. c The expression of Ampk was significantly promoted in hAMSCs group. d No obvious difference of p-Akt and Akt expression was observed between groups. e Expression of FoxO3a in oocyte were determined by immunofluorescence experiments. stronger signals were observed in hAMSCs group. NS: Normal saline group; HSA: $1 \%$ human serum albumin group; hAMSCs: hAMSCs transplantation group ( $7.5 \times 106$ cells/kg body weight). Scar bar: $100 \mu \mathrm{m} . \mathrm{n}=6$. error bars indicate SEM. Different lowercase letters represent significantly statistical differences $(P<0.05)$.

\section{Supplementary Files}

This is a list of supplementary files associated with this preprint. Click to download.

- FiguresS1.tif

- FiguresS2.tif 